\title{
The Natural Resources Damaged Study of Protection in Changli Gold Coast National Nature Reserve
}

\author{
Yun Zhang ${ }^{1, \text { a }}$, Xiaoqing $\mathrm{Han}^{2, \mathrm{~b}}$, Yujuan $\mathrm{Chu}^{3, \mathrm{c}}$, Jing $\mathrm{Li}^{4, \mathrm{~d}}$, \\ Weiming $\mathrm{Gao}^{1, \mathrm{e}_{\star}}$ (Corresponding Author), Jie $\mathrm{Gao}^{1, \mathrm{f}}, \mathrm{Min} \mathrm{Gao}^{1, \mathrm{~g}}$, Yidan $\mathrm{Cao}^{1, \mathrm{~h}}$, \\ Lei Zhao ${ }^{1, i}$, Xinyu Duan ${ }^{5, j}$ and Hongwei Bao ${ }^{5, k}$ \\ ${ }^{1}$ Hebei Key Laboratory of Environmental Change and Ecological Construction, College of \\ Resources and Environmental Science, Hebei Normal University, Shijiazhuang 050024, China; \\ ${ }^{2}$ Hebei Utilization and Planning Institute of Land Resources, Shijiazhuang 050051, China; \\ ${ }^{3}$ No.2 Experimental Middle School of Shijiazhuang, Shijiazhuang 051130, China; \\ ${ }^{4}$ Hebei Jiaotong Vocational and Technical College, Shijiazhuang 050000, China; \\ ${ }^{5}$ Changli Golden Beach National Ocean Natural Preserve, Changli 066600, China. \\ azhangy1024@126.com, \\ bxqhan312@126.com, ${ }^{\mathrm{b}} \mathrm{chu}$ yujuan@126.com, ${ }^{\mathrm{d}} 961927950 @ q q . c o m,{ }^{\mathrm{e}^{*}}$ gaowmd@263.net, ${ }^{\mathrm{f}} 95702$

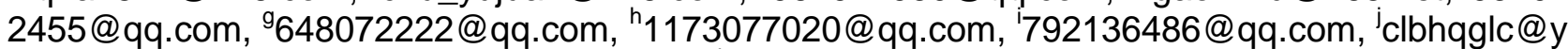 \\ ahoo.com.cn, ${ }^{k} 1628188369 @ q q . c o m$
}

Keywords: natural resources; damaged situation; Changli County; Gold Coast National Nature Reserve.

\begin{abstract}
In order to study the damaged situation of the objects of protection, this paper analyzed the natural resources of Changli Gold Coast National Nature Reserve, and took the method of both collating data indoors and field investigation to study the objects of protection. The results showed that there were 8 kind objects of protection, Coastal dunes and Qilihai Lagoon and Beaches and Sea water and sea creatures and Amphioxus and the protective coast-forest and Birds and Luanhe wetland. The current situation of mainly protection objects kept the better condition which protected the established of protection played an important role for the protection of objects.
\end{abstract}

\section{Introduction}

The Changli Gold Coast National Nature Reserve was established as one of five national Marine type nature reserve on September 30, 1990 by the State Council. It locals along the east coast with the area of $300 \mathrm{~km}^{2}$ in the east northeast of Changli County, Qihuangdao City [1-3]. The mainly protection objects are natural landscape and ecological environment and natural resources of sandy coast which are composed by Amphioxus, Coastal dunes, Lagoon, sea creatures, coast-forest, Birds, wetland and so on. It has been the typical coastal sea to study marine dynamic process and changes in the land and sea, and it also has important ecological value and scientific and ornamental value.

\section{The damaged situation of natural resources}

Coastal dunes. The coastal dunes are the most distinctive landscape in Changli Gold Coast National Nature Reserve which are the unique even in our country and rare landscapes in the world with the scale and continuity. Due to the characteristics of coastal dunes, there are the natural laboratories for coastal landscape development process such as ocean dynamics and ocean dynamics.

The coastal dunes, with 1 to $2 \mathrm{~km}$ width and $40 \mathrm{~km}$ length, are distributed as chain in close to the coast. The main dune, named Dayuding, is the very typical mobile sand dune, and it moves towards from NNE to SSW with 100 to $200 \mathrm{~m}$ width nearby the coast. The height of Dayuding is about $40 \mathrm{~m}$, and it gradually reduces to 20 to $30 \mathrm{~m}$ to the south and $20 \mathrm{~m}$ to the south. It's only about $10 \mathrm{~m}$ near the 
Luanhe Delta. Meanwhile, the grade of the main dune is about 20 to 25 degrees in the sea side, and 30 to 32 degrees in the other side.

The coastal dunes are mainly made of fine medium sand and medium-fine sand. The mean

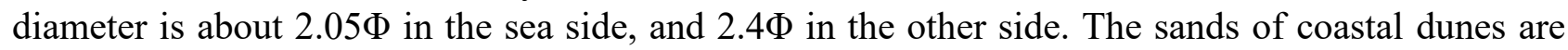
form Luanhe River, and the heavy mineral combination are garnet and hornblende and epidote, the same with position of the end of Luanhe River, where contains more of bead sands.

The main dune is still active in the south of Xinkaihe Estuary. Due to effect of reduced sources and human disturbances, it moves towards to land with the height and slope reduced gradually, both in the sea side and land side, under the prevail winds. The low sand dunes have been fixed by the shelter forest inside the main dune, however, they are till semi-fixed of the transition zone.

Qilihai Lagoon. Qilihai Lagoon is one of the only modern lagoon in China. It's the lagoon ecosystem which is made of water body, the lake aquatic organisms, waterfowl and migratory birds. Due to which, it's the typical representative of the coastal lagoon. Meanwhile, it locates in the sea and land interaction area, greatly influenced by sea land dynamic change and human activities, where the environment changes quickly with agent complex, and now it's the perfect place to study wetland formation, evolution and degradation.

Qilihai Lagoon lies inside the dune zone the middle-south of protect area. It's the semi-closed lagoon with the tidal channel connected with the sea in the northeast corner. There are many geomorphic types such as the beach of lake, the basin of lake, the embankment of lake and tidal channel. Meanwhile, there are 5 seasonal rivers pouring into the Qilihai Lagoon, including Zhaojiaganggou River, Nijinggou River, Liutaigou River, Daozigou River, Liutuogou River and so on. The highest water level is $2.05 \mathrm{~m}$, the lowest tide level is $0.53 \mathrm{~m}$, and the average tidal range is $0.70 \mathrm{~m}$ [4-6]. There is many vegetation, mainly as reed, in the lakeshore nearby the offshore area. The Qilihai Lagoon and forest and the around fishing ports make up ecosystem, which provides the habitat for swimming bird, tidal flats waders, forest songbirds and home birds.

There is the largest fishing port, named Xinkaikou Port, with the length of $850 \mathrm{~m}$ and 1500 fishing boats berthed in the north of tidal channel. Because of the building of fishing port, the width of lagoon reduces from $500 \mathrm{~m}$ to about $100 \mathrm{~m}$, and the property changes from natural tidal channel into the canal, which reduce the tidal volume and change the tide process and accelerated the deposition of Qilihai Lagoon.

Beaches. The beaches are famous as wide area, slow slope, soft sand beach, tidal flat and clear water for home and world. Meanwhile, it's named the kiss mark of desert and sea. In 2005 it's voted as one of the 8 most beautiful coast of China by Chinese national geography magazine. And now it's the very high value of tourism and rest.

The beach lies on the east of coastal dune with the width about 50 to $120 \mathrm{~m}$, and it changes into above $500 \mathrm{~m}$ from Dapuhe Rive to Xinkaikou River, and the slope is less than $5^{\circ}$, however it's about $5^{\circ}$ to $8^{\circ}$ in high tidal flat. Meanwhile, it's mainly made up fine sand with $2.0 \Phi$ median size. Except that, there are several offshore sand banks under the water outside of the beach, which are the protect zone of the beach. The offshore band banks extend as strip with 1 to $3 \mathrm{~m}$ relative height, 20 to $60 \mathrm{~m}$ width and $2.9^{\circ}$ slope [7]. Meanwhile, they have been rushed into the scarp slope in the seaward beaches, which are mainly made up medium-fine sand, $1.9 \Phi$ median size, with few shells and debris.

Sea water and sea creatures. The sea water quality condition is good in the whole and matches the I water quality standard. However, it is over II water quality standard of total phosphorus in summer and winter. It' $s$ the middle level of biodiversity, the normal temperate productivity level of primary productivity and the normal level of the phytoplankton community in north China where is not abnormal phenomenon. In the meanwhile, it is the typical coastal sandy and sediment community of large benthic animal, and mainly as small ones with high perched density and low biomass.

At present, the protect area is faced with several environmental pressures, such as overfishing, aquaculture pollution, agricultural non-point source pollution, pollutant emission from the Luanhe River, coastal zone habitat destruction and so on. The pollutants, from large scale and high density scallop culture, strongly effect the growth and development of all kinds of marine lives. 
Amphioxus. Amphioxus, the protected second class animal in the country, is the Appendicularia of Cephalochordate of Vertebrate, and it was the ancestors of chordate before 5 hundred million years ago, it' s also the typical transitional specimen evolution from invertebrates to vertebrates. Charles Robert Darwin said that the discovery of amphioxus was a great discovery which was the key to instructions of vertebrate origin and the living fossil in the research of biological evolution.

The reserve area is the mainly habitat for amphioxus in the Bohai Sea. The average inhabit density of amphioxus is $611 / \mathrm{m}^{2}$ and the average biomass is $17.7 \mathrm{~g} / \mathrm{m}^{2}$ which shows the condition of well grown amphioxus population and normal age structure. Influenced by the factors since 2002, such as reducing the volume of suspended sediment, increasing raft cultivation around the reserve waters, pollutant emission and sand excavating by people, the seawater environment and the types of sediment of amphioxus habitat have been changed, meanwhile, the sedimentary type area of amphioxus habitat has been downsizing and fragmentation which means the inhabit density and biomass of amphioxus has been reduced year by year. By 2009 the average inhabit density of amphioxus reduced to $45 / \mathrm{m}^{2}$, and average biomass of amphioxus was $3.4 \mathrm{~g} / \mathrm{m}^{2}$, and high density distribution area is broken.

The protective coast-forest. The protective coast-forest has many ecological functions such as windbreak and sand-fixation, water conservation, local climate improved, birds habitat, biodiversity increased. At the same time, it also has the function to coordinate the natural landscape, optimize the environment of coastal dunes, formed the coastal tourism resources which influences the coastal ecological environment and is the model of harmonious coexistence between man and nature.

The protective coast-forest has been planted in the 1950s to 1960s, and the main type are Black locust and Poplar and Amorpha fruticose.

The man-made Black locust forest grows well with neat appearance and simple structure. As the dominant species of acacia tree layer, the average height of Black locust forest is $8 \mathrm{~m}$ to $12 \mathrm{~m}$ and the crown density is about $70 \%$ to $90 \%$. There are less species of auxiliary species, and the mainly type are the Black locust and the Shrubs acacia of sapling with the height of $1.1 \mathrm{~m}$ to $1.8 \mathrm{~m}$ and the cover degree of $25 \%$. Meanwhile, there are some community constructive species, such as Hebei popular, Canada poplar, Simon poplar and so on. The average height of arborous layers is $20 \mathrm{~m}$ to $25 \mathrm{~m}$ and the cover degree is about $65 \%$ to $75 \%$. The Black locust bush woods grow well with tidy physiognomy and sample bush layer kind which the average height is $1.2 \mathrm{~m}$ to $1.8 \mathrm{~m}$ and the cover degree is about $55 \%$ to $65 \%$.

The ecological system of coast-forest is fragile and the anti-interference ability is in protect area. Limited by site conditions, such as sand soil, poor water, strongly wind and so on, they grow not well with poor natural regeneration ability and withered trunk. In depression between mounds, because of the high underground water level, the salt in the water seriously inhibits the growth of trees. At the same time, the density and area are reduced year by year by the unreasonable cutting and squat. The integrity and continuity of the community are broken, and the fragmentation are improved by the coastal highway which cross the protective forest. Meanwhile, the space of protect forest are reduced continuously due to all kinds of tourist activities. The development of marine culture ponds in supratidal zone cause the soil secondary salinization which lead to the death of protective forest.

Birds. Birds, the very important components of the coastal ecological system, play an important role to sustain biodiversity and ecological balance. The protection area lies in the intersection of migrant birds from north to south and from east to west. There are covered by many kinds of vegetation and a large area of wide mud flat. Except that, there are less human activity. Due to which there are many kinds of birds and many of them are rare species. By now there have been found 19 orders and 62 families and 380 species, amount which there are more than 60 kinds of national key protection of birds, such as Saunders' Gull, red-crowned cranes, crane, white stork, ern, whooper swans, pied harrier and so on, so it is one of the most famous place to view birds at home and abroad [8]. Due to the founded of the protection area, bird habitat has been well preserved in the whole, and the composition and quantity of birds have been in the stable condition in relatively, except in local area birds habitat has been changed because of the plant and cultivation producing activity. 
Luanhe wetland. Luanhe wetland, lies in the south of protection area, is the estuarine wetland for complete development sedimentary type and unique landforms combination. And it has high academic value in many domains, such as geomorphology, sedimentology, hydrologic geology and so on. Luanhe wetland lies in the intersection of migrant birds from north to south and from east to west, and there are about 240 kinds of birds, among of which there are 12 species of national first class protected birds and 50 species of the second class. Especially there is the gathering place of Saunders' gull which has been the endangered creatures in the world and taken more attention by the world wildlife fund.

\section{Summary}

This paper takes the method of both collating data indoors and field investigation to study the natural resources damaged situation in Changli Gold Coast National Nature Reserve. The results show that the 8 kind objects of protection keep the better condition which protect the established of protection played an important role for the protection of objects.

\section{Acknowledgment}

This paper is supported by the project of the study of evolution characteristic and environmental effect of the mainly protection objects in Changli Gold Coast National Nature Reserve (14273303D).

Foundation: The study of evolution characteristic and environmental effect of the mainly protection objects in Changli Gold Coast National Nature Reserve (14273303D)

\section{References}

[1]. HAN Xiaoqing, GAO Weiming, “The Processing of Scanning Topographic Maps Based on ERDAS IMAGINE”, Remote Sensing Technology and Application, Vol. 6, 2007, pp. 748-752.

[2]. Han Xiaoqing, GAO Weiming, CHU Yujuan, "Investigation of the natural sandy coast erosion: a case study of hebei province”, Marine Geology and Quaternary Geology, No. 3, 2011, pp. 23-29.

[3]. Fenghua Zhao, Xu Ling, "The study of development and utilization of tourism resource in Hebei Province”, Enterprise of Hebei. 6 (2014) 49-50.

[4]. Han Xiaoqing, Li Jing, Zhang Yun, et al, "Evolvement of the muddy coastline and theirs environmental effects in Hebei Province”, Marine Sciences, Vol. 35, No. 11, 2011, pp. 11-18.

[5]. J. Dumanski, C. Pieri, "Land quality indicators: research plan”, Agriculture, Ecosystems \& Environment, vol.81, 2000, pp. 93-102.

[6]. D. F. Acton, L. J, "Gregorich, Executive summary of the health of our oil toward sustainable agriculture in Canada, Ottawa:Research Branch:Centre for land and Biological Resources Research”, Agriculture and Agri-Food Canada, 1996.

[7]. L. J. Hunt, I. M. Dutton, J. P. Duff, “Integrated Coastal Zone Planning and Management Manual Vaughn International”, Canora and BCEOM, Jakarta CD ROM (bilingual), 1998.

[8]. R. Dahuri, I. M. Dutton, “Integrated coastal management enters a New Era in Indonesia”, Integrated Coastal Zone Management, Vol. 1, 2000, pp. 11-16. 